\title{
Generation of Entrepreneurship Environments for New Product Development
}

\author{
Cristina Martin-Doñate ${ }^{1(\otimes)}$, Fermín Lucena-Muñoz ${ }^{2}$, \\ Lina Guadalupe García-Cabrera ${ }^{3}$, and Jorge Manuel Mercado-Colmenero ${ }^{1}$ \\ ${ }^{1}$ Department of Engineering Graphics, Design and Projects, University of Jaén, \\ Campus Las Lagunillas, s/n, 23071 Jaen, Spain \\ cdonate@ujaen.es \\ 2 Department of Management, Marketing and Sociology, University of Jaen, \\ Campus Las Lagunillas, s/n, 23071 Jaen, Spain \\ 3 Department of Computer Sciences, University of Jaen, Campus Las Lagunillas, s/n, 23071 \\ Jaen, Spain
}

\begin{abstract}
The economic environment demands companies to be able of innovating and presenting new products and technologies. However, current industrial environments are composed of big established companies, small or medium family businesses and regional clusters. This business map does not comply with the dynamism required for detecting needs and proposals in form of new products that meet the current customer requirements. The creation of start-ups in the field of engineering is considered as a possibility to cover a growing market in designing high technological products. However, despite the importance and economic impact of the start-ups for less industrialized environments the courses in the engineering field do not include activities that contextualize theoretical knowledge and entrepreneurship. The paper presents the results of creating an entrepreneurial environment focused on the student as entrepreneurial unit. In this context, a series of new activities based on new design proposals have been developed on the basis of new technical solutions for industrial companies. The new designs have been presented as minimum viable products. The technical knowledge required for making the new designs has been complemented with entrepreneurial training. The results show an increase in students' willingness to create small companies based in new products as an employment option at the end of their studies.
\end{abstract}

Keywords: Industrial design · Entrepreneurship - CAD · Product development

\section{Introduction}

An entrepreneur in new product design must have the skills of both an industrial designer and a business manager [1]. Currently the field of entrepreneurship has taken importance as a mean of self-employment in the field of new product development. Unfortunately, academic education mainly focuses on the learning of CAD modelers and technical subjects. Design learning has focused on preparing professionals according to this technical profile. The four main components of NPD (New Product Development) are classified 
into: Research, Design (including engineering and industrial design) [2, 3], Marketing [4] and Manufacturing [5,6]. These tasks are usually developed by specialists, especially in big companies with large-scale projects. However, the demand for small-scale projects increases every day, there being a great need for engineers with an adaptable profile and flexible skills. The business professional in new product design demands a changing mod-el of learning. This trend presents very different boundary conditions compared to the past industrial landscape that created the field of product design. Currently there are many more options available for engineers, in addition to working for big companies or design consultancies. In business environments engineers must have skills related to creativity, sustainability [7] and management of human resources. Industry requires professionals with technical experience, and the ability to pro-vide new ideas generating demand through innovation. At the moment students can produce and manufacture their own designs or work with colleagues to create a start-up company.

The development of skills in entrepreneurship for engineering environments requires a change of the educational process. However, and although university institutions are the most important part of this process, actions for the development of entrepreneurship are usually complemented by initiatives by other institutions outside the education system. The entrepreneur engineer must be able to evaluate possible solutions, use software tools adequately, learn to work in team, and use efficiently communication skills to work with other people. In addition, the engineer must have the ability to conceptualize and turn the concept into reality. The development of the entrepreneurship in engineering requires a big change in the learning processes linking educational and research areas to enhance creative processes and practices [8].

This paper presents the results of the activities carried out with the objective of developing business capacity in mechatronic engineering students through the introduction of new activities related to entrepreneurship in the field of new product development. The designs presented technical solutions to problems performed for industrial companies. The design results have been presented in the form of prototypes complementing the projects with product business models.

\section{Methodology}

A great quantity of engineering students wants to develop their work in big companies. However, it is not always possible to find a qualified job in this area especially in less industrialized environments. Additionally, engineering students usually do not have the knowledge to create a new small company, mainly be-cause they have a technical profile. In this line, a series of activities have been proposed, consisting of create and design innovative products obtaining its business plan.

The objective of these activities has been to motivate and prepare engineering students in using industrial design as a tool for self-employment. Several industrial companies have collaborated in the entrepreneurship activities. These companies presented to the engineering student's technical problems related to needs to design to solve Fig. 1.

As a complement to the student's training in entrepreneurship issues several workshops related to business model methodologies were presented. These work-shops were taught by lecturers of the area of business and industrial engineers experts in 


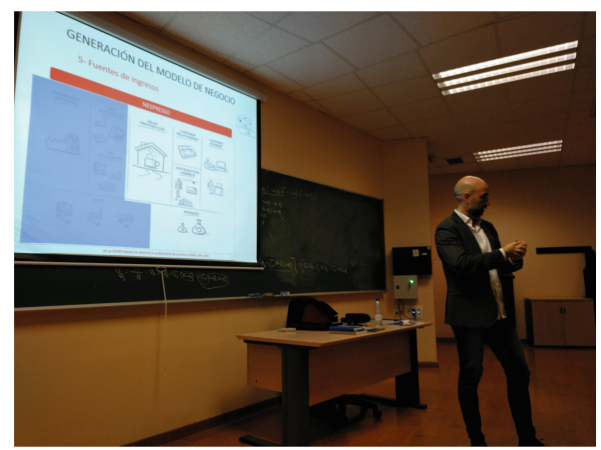

Fig. 1. Presentation of the technical problems

entrepreneurship. The objective was to help the students to understand that the product concept is only one part of the process of creating a startup. The tool to propose the business model based on product design was the Canvas methodology. The Canvas method is a practical and simple tool that allows obtaining a global analysis of all the important aspects that make up the business model, working on problems as a team. This method is based on the analysis of the boundary conditions in which the company is going to work: identifying the target client; how to reach customers and finally the means of payment. The set of entrepreneurial activities were complemented with workshops taught by staff experienced in entrepreneurship (Fig. 2), and several visits to entrepreneurs where students were able to discuss their doubts with entrepreneurs with experience in creating a startup.

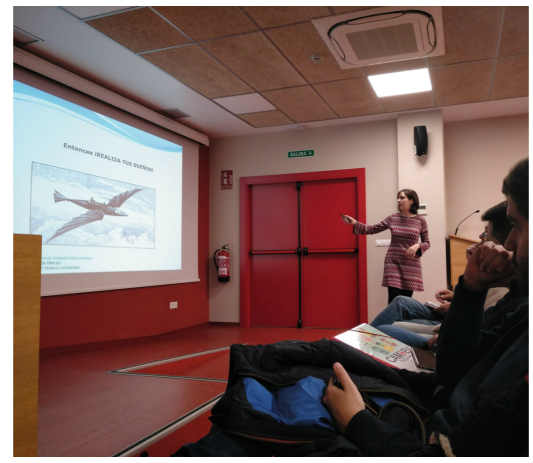

Fig. 2. Workshops taught by staff experienced in entrepreneurship

Team students created different product proposals by using CAD tools and new products methodology. Finally, the designs in form of a minimum viable product together with the business plan were presented to the companies which assessed the students, commenting on possible improvements in both product and business area. A total of 20 different proposals were presented by teams formed by five students. In Fig. 3 two of the products presented to the companies are shown. 

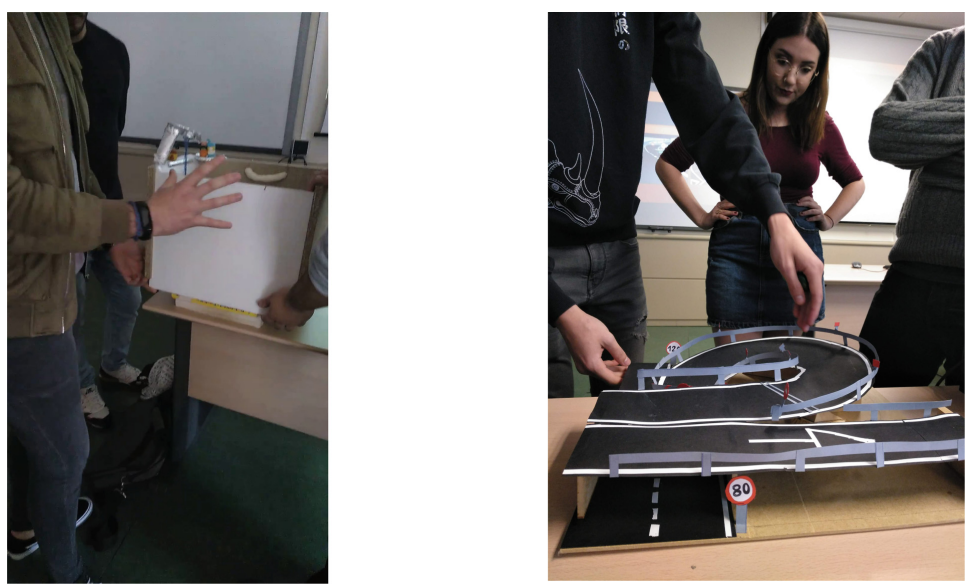

Fig. 3. Presentation of the developed products by the students

\section{Results}

In order to evaluate the influence of the performed activities in the entrepreneurial skills and the intention for creating a new start up, a survey was conducted on the ILIAS platform for the students that had participated in these activities. ILIAS is an opensource web-based learning management system (LMS) that supports learning content management (including SCORM 2004compliance) and tools for collaboration, communication, evaluation and assessment [9]. The inter-views were completed voluntarily by all the students that have participated in the activities, being a total number of 15 participant students (13 males and 2 female) from different working design teams.

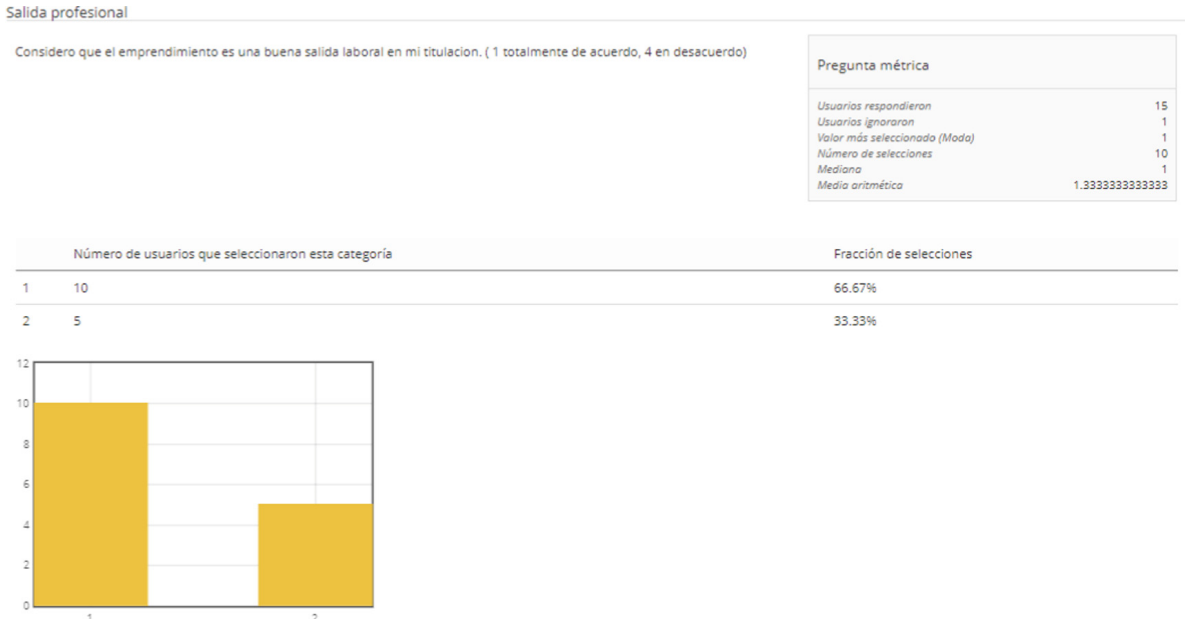

Fig. 4. Survey results 
Students were asked about considering creating a start up at the end of their studies. $66,6 \%$ of the students that participate in the activities wanted to create a new start up after they finish their studies, with a $66,6 \%$ totally agreeing and 33,3\% agreeing. The results of the survey have been indicated in Fig. 4.

\section{Conclusions}

Develop entrepreneurial skills in engineering needs of a big change in training activities in order to integrate educational and industries to generate new creative processes and practices. The paper presents the results of creating an entrepreneurial environment focused on the student as entrepreneurial unit. In this context, a series of new activities based on new design proposals have been developed on the basis of new technical solutions for industrial companies. The new designs have been presented as minimum viable products. The technical knowledge required for making the new designs has been complemented with entrepreneurial training. The results show an increase in students' willingness to create small companies based in new products as an employment option at the end of their studies. Students were asked about considering creating a start up at the end of their studies. $66,6 \%$ of the students that participate in the activities would like to create a new start up after they finish their studies.

Acknowledgments. This research work was supported by the University of Jaen with the Plan de Apoyo a la Transferencia del Conocimiento, el Emprendimiento y la Empleabilidad (2019-2020) AC- 10 through the project "Creation of an entrepreneurial ecosystem of microstart-ups based on innovative products".

\section{References}

1. Huang-Saad, A.Y., Morton, C.S., Libarkin, J.C.: Entrepreneurship assessment in higher education: a research review for engineering education researchers. J. Eng. Educ. 107(2), 263-290 (2018)

2. Mercado-Colmenero, J.M., Rubio-Paramio, M.A., la Rubia-Garcia, M.D., Lozano-Arjona, D., Martin-Doñate, C.: A numerical and experimental study of the compression uniaxial properties of PLA manufactured with FDM technology based on product specifications. Int. J. Adv. Manufact. Technol. 103(5-8), 1893-1909 (2019)

3. Fayolle, A., Lamine, W., Mian, S., Phan, P.: Effective models of science, technology and engineering entrepreneurship education: current and future research. J. Technol. Transfer, 1-11 (2020)

4. Martin-Doñate, C., Lucena-Muñoz, F., Gallego-Alvarez, J.: Integration of marketing activities in the mechanical design process. In: Advances on Mechanics, Design Engineering and Manufacturing, pp. 961-969. Springer, Cham (2017)

5. Mercado-Colmenero, J.M., Martin-Doñate, C., Rodriguez-Santiago, M., Moral-Pulido, F., Rubio-Paramio, M.A.: A new conformal cooling lattice design procedure for injection molding applications based on expert algorithms. Int. J. Adv. Manufact. Technol. 102(5-8), 1719-1746 (2019) 
6. Doñate, C.M., Paramio, M.R.: New methodology for demoldability analysis based on volume discretization algorithms. Comput. Aided Des. 45(2), 229-240 (2013)

7. Kuckertz, A., Wagner, M.: The influence of sustainability orientation on entrepreneurial intentions - investigating the role of business experience. J. Bus. Ventur. 25(5), 524-539 (2010)

8. Poggesi, S., Mari, M., De Vita, L., Foss, L.: Women entrepreneurship in STEM fields: literature review and future research avenues. Int. Entrepreneurship Manag. J. 16(1), 17-41 (2020)

9. https://www.ilias.de/en/

Open Access This chapter is licensed under the terms of the Creative Commons Attribution 4.0 International License (http://creativecommons.org/licenses/by/4.0/), which permits use, sharing, adaptation, distribution and reproduction in any medium or format, as long as you give appropriate credit to the original author(s) and the source, provide a link to the Creative Commons license and indicate if changes were made.

The images or other third party material in this chapter are included in the chapter's Creative Commons license, unless indicated otherwise in a credit line to the material. If material is not included in the chapter's Creative Commons license and your intended use is not permitted by statutory regulation or exceeds the permitted use, you will need to obtain permission directly from the copyright holder.

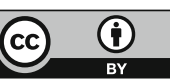

